\title{
IMUNOMARCAÇÃO DE TGF- $\beta$ EM PRÓSTATAS CANINAS NORMAIS E COM LESÕES PROLIFERATIVAS
}

\section{IMMUNOEXPRESSION OF TGF-B IN NORMAL CANINE PROSTATES AND WITH PROLIFERATIVE LESIONS}

\author{
Denise Caroline Toledo ${ }^{1}$ ORCID - http://orcid.org/0000-0001-9807-8495 \\ Mariana Batista Rodrigues Faleiro1 ORCID - http://orcid.org/0000-0003-2589-1308 \\ Hugo Henrique Ferreira ${ }^{1}$ ORCID - http://orcid.org/0000-0002-4431-9617 \\ Adriana Marques Faria1 ORCID - http://orcid.org/0000-0002-8129-2476 \\ Moema Pacheco Chediak Matos ${ }^{1}$ ORCID - http://orcid.org/0000-0002-4907-4612 \\ Renee Laufer Amorim² ORCID - http://orcid.org/0000-0002-8653-7938 \\ Veridiana Maria Brianezi Dignani De Moura1* ORCID - http://orcid.org/0000-0001-7128-7035 \\ 1 Universidade Federal de Goiás, Goiânia, GO, Brasil. \\ ${ }^{2}$ Faculdade de Medicina Veterinária e Zootecnia - UNESP, Botucatu, SP. Brasil. \\ *Autora para correspondência - vdmoura@hotmail.com
}

\section{Resumo}

O fator de crescimento transformador- $\beta$ (TGF- $\beta$ ), um mediador do crescimento prostático, induz a angiogênese e inibe a proliferação celular. Neste estudo, esse marcador foi utilizado com o objetivo de avaliar sua imunomarcação no tecido normal e com lesões proliferativas benignas, pré-neoplásicas e neoplásicas da próstata canina. Para isso, foram selecionadas 54 glândulas com histomorfologia normal, hiperplasia prostática benigna (HPB) epitelial, HPB estromal, atrofia inflamatória proliferativa (PIA), neoplasia intraepitelial prostática (PIN) e carcinoma, utilizadas para a confecção de um bloco de microarranjo tecidual (Tissue Microarray - TMA). As lâminas de TMA foram submetidas à técnica de imunoistoquímica com o anticorpo anti-TGF- $\beta$, sendo avaliada a intensidade de imunomarcação nas células epiteliais e estromais. Houve imunomarcação de TGF- $\beta$ no tecido normal e naqueles com lesões proliferativas. Maior imunomarcação de TGF- $\beta$ foi constatada nas células do tecido prostático normal e com HPB, enquanto as células prostáticas com PIA, PIN e carcinoma exibiram menor imunomarcação dessa citocina, o que sugere a ação do TGF- $\beta$ na manutenção da homeostase do tecido normal e com lesão proliferativa benigna e na progressão das lesões proliferativas pré-malignas e malignas da próstata canina.

Palavras-chave: carcinoma, fator de crescimento, imunoistoquímica, PIA, PIN.

\begin{abstract}
The transforming growth factor- $\beta$ (TGF- $\beta$ ), a mediator of prostatic growth induces angiogenesis and inhibits cell proliferation. It was used in this study in order to evaluate its expression in normal prostatic tissue and those with benign proliferative lesions, pre-malignant and malignant prostatic diseases. A total of 54 glands with normal histomorphology, epithelial benign prostatic hyperplasia $(\mathrm{BPH})$, stromal $\mathrm{BPH}$, prostatic inflammatory atrophy (PIA), prostatic intraepithelial neoplasia (PIN), and adenocarcinoma were selected and used in the tissue microarray block (TMA). The TMA slides were subjected to the immunohistochemistry with anti-TGF- $\beta$ and its staining intensity in epithelial and stromal cells was evaluated. There was TGF- $\beta$ immunostaining by both normal tissues and
\end{abstract}


those with proliferative lesions. Higher TGF- $\beta$ immunostaining was observed in cells from normal prostatic tissues and with HPB, whereas prostatic cells with PIA, PIN and carcinoma exhibited lower immunostaining of this cytokine, suggesting the action of TGF- $\beta$ in the maintenance of normal tissue homeostasis and with benign proliferative lesion and in the progression of pre-malignant and malignant proliferative lesions of the canine prostate.

Keywords: carcinoma, immunohistochemistry, growth factor, PIA, PIN.

Recebido em: 17 de março de 2015

Aceito em: 6 de maio de 2019

\section{Introdução}

À semelhança do que ocorre na espécie humana, as doenças prostáticas têm sido frequentemente observadas na próstata canina e são comuns em cães não castrados adultos e idosos ${ }^{(1)}$. As lesões proliferativas na próstata canina incluem a hiperplasia prostática benigna (HPB), a atrofia inflamatória proliferativa (PIA), a neoplasia intraepitelial prostática (PIN) e o adenocarcinoma ${ }^{(1-3)}$.

A HPB compreende a principal afecção prostática em cães adultos não castrados ${ }^{(1)}$. A PIAé considerada uma lesão pré-maligna devido às similaridades morfológicas com o carcinoma prostático e por envolver fatores potencialmente carcinogênicos, como a inflamação ${ }^{(4)}$. Da mesma forma, a PIN consiste em uma lesão displásica do epitélio secretor da próstata, apresentando atipias celulares semelhantes àquelas do adenocarcinoma ${ }^{(5)}$. Quanto aos carcinomas prostáticos, estes ocorrem frequentemente no homem e podem se desenvolver espontaneamente no cão ${ }^{(6,7)}$, em que comumente apresentam comportamento agressivo e, muitas vezes, estrutura glandular ou acinar, sendo classificados como adenocarcinomas ${ }^{(6)}$.

O fator de crescimento transformador beta $(\mathrm{TGF}-\beta)$ é uma citocina relacionada a uma variedade de processos biológicos como apoptose, tumorigênese, proliferação, diferenciação e expressão gênica ${ }^{(8)}$.É responsável por inibir a proliferação de diversos tipos celulares, especialmente as linhagens epiteliais. Nesse contexto, as células do tecido prostático neoplásico são reconhecidamente moduladas por essa citocina $^{(9)}$.

O TGF- $\beta$ é sintetizado por diferentes células, incluindo linfócitos, macrófagos, fibroblastos, células musculares lisas, condrócitos, astrócitos, células epiteliais, plaquetas e ainda células tumorais ${ }^{(10)}$. Ainda, de acordo com Niu et al. ${ }^{(11)}$, o TGF- $\beta$ acumula-se nas células estromais, fator que contribui para a proliferação celular e a progressão das lesões proliferativas que ocorrem na próstata. Contudo, para Lee et al. ${ }^{(9)}$, o modo de ação do TGF- $\beta$ no tecido prostático é variável.

Diante disso, este estudo avaliou a imunomarcação de TGF- $\beta$ na próstata canina visando melhor compreender sua ação no tecido prostático normal e com lesões proliferativas, incluindo HPB (epitelial e estromal), PIN, PIA e carcinoma.

\section{Material e métodos}

Foram colhidas 150 próstatas de cães adultos, não castrados, com ou sem histórico clínico de doença prostática e provenientes da rotina necroscópica de dois laboratórios de patologia animal. Após a colheita, as glândulas foram identificadas e inicialmente seccionadas em um corte transversal na 
porção média, para melhor penetração do fixador. Quando maior que $3 \mathrm{~cm}$ de diâmetro, a próstata foi submetida a dois cortes, obtendo-se três porções - cranial (PCr), medial (PM) e caudal (PCa).

As glândulas foram fixadas em formalina tamponada a 10\% durante 48 horas, recortadas, acondicionadas em cassetes e mantidas em álcool $70^{\circ}$ até o processamento e inclusão em parafina. Em seguida, foram confeccionados cortes histológicos de $3 \mu \mathrm{m}$, os quais foram distendidos sobre lâminas histológicas e corados por hematoxilina e eosina (HE) para a avaliação histomorfológica.

$\mathrm{Na}$ avaliação histomorfológica foram selecionadas amostras de próstatas normais $(n=7)$ e com lesões proliferativas, estas de acordo com critérios de Fonseca Alves et al. ${ }^{(1)}$ para HPB (epitelial $\mathrm{n}=10 \mathrm{e}$ estromal $n=6$ ), Toledo et al. ${ }^{(3)}$ para PIA (discreta $n=5$, moderada $n=6$ e acentuada $n=5$ ), Bostwick e Qian $^{(5)}$ para PIN $(n=7)$ e Sugar ${ }^{(12)}$ para carcinoma $(n=8)$, totalizando 54 próstatas. A análise foi realizada em microscópio óptico, inicialmente em menor aumento $(32 \mathrm{x})$, seguindo aos aumentos de 100x, 200x e 400x.

As amostras provenientes das 54 próstatas foram utilizadas para a confecção do bloco de microarranjo tecidual (TMA), em duplicata, e realização da técnica de imunoistoquímica e imunomarcação de TGF- $\beta$. As amostras foram marcadas nas lâminas de referência (HE) e identificadas nos blocos doadores, dos quais foram retirados cilindros (cores) de $1 \mathrm{~mm}$ de diâmetro (Tissue MicroArray builder 20010.2, Histopathology Ltd, Hungary), correspondentes às áreas marcadas, e transferidos para o bloco receptor (TMA), conforme descrito por Kononen et al. ${ }^{(13)}$ e Bubendorf et al. ${ }^{(14)}$. No bloco receptor também foi incluída uma amostra de placenta humana normal para a orientação da leitura das amostras nas lâminas de TMA.

Do bloco de TMA foram obtidos cortes de $3 \mu \mathrm{m}$, estes distendidos sobre lâminas silanizadas (Starfrost White, Sakura, ready to use, Germany - Dako 9545-1) e submetidos à coloração de HE para a confirmação das lesões selecionadas na avaliação histomorfológica, e à técnica de imunoistoquímica para a avaliação da imunomarcação de TGF- $\beta$.

Uma lâmina de TMA, com amostras em duplicata, foi diafanizada em três imersões sequenciais de xilol, durante 30 minutos cada, à temperatura ambiente. Em seguida, foi submetida a passagens sequenciais em álcool $\left(100^{\circ} \times 3,95^{\circ} \times 1,85^{\circ} \times 1\right.$ e $\left.70^{\circ} \times 1\right)$, por cinco minutos cada. Na próxima etapa, com o intuito de reduzir coloração de fundo, a lâmina foi incubada por cinco minutos em solução de dodecil sulfato de sódio (SDS) e lavada em água destilada.

Para a recuperação antigênica, a lâmina foi submersa em solução tampão EDTApH 8.0, a $96^{\circ} \mathrm{C}$, durante 25 minutos, em banho-maria. Após o arrefecimento, foi lavada em água destilada e submetida ao bloqueio da peroxidase endógena por imersão em solução de peróxido de hidrogênio a $10 \%$ (10 ml de H2O2/90 ml de metanol), por 10 minutos. Seguiram-se o bloqueio das marcações inespecíficas (BSA a $1 \% / 1$ h e solução de leite em pó desnatado a 10\%/1h30min - Molico ${ }^{\circledR} 10 \mathrm{~g} / 100 \mathrm{ml} \mathrm{H} \mathrm{H}_{2} \mathrm{O}$ destilada), e a incubação com o anticorpo primário anti-TGF- $\beta$ (mouse monoclonal antibody transforming growth fator beta, clone 17, \#NCL-TGFB, Novocastra), na concentração de 1:50 (Antibody diluent, ADS125, Spring), em câmara úmida por 18 horas, à temperatura de $4{ }^{\circ} \mathrm{C}$. Nos cortes utilizados como controle negativo, o anticorpo primário foi substituído por solução tampão TRIS pH 7,4 e placenta como controle positivo da reação.

As etapas seguintes consistiram da incubação com anticorpo secundário (Advance System, Dako K4068) em câmara úmida, à temperatura ambiente, durante 30 minutos, e da revelação da reação em solução de diaminobenzidina (DAB, Dako K3468-1), por três minutos. Entre as etapas, as lâminas foram lavadas em solução tampão TRIS pH7,4. Seguiram-se a contracoloração em hematoxilina de Harris por 20 segundos; a lavagem em água destilada; a desidratação em banhos de álcool $\left(85^{\circ} \times 1\right.$, $95^{\circ} \times 1$ e $\left.100^{\circ} \times 3\right)$, por cinco minutos cada, e de xilol, durante cinco minutos cada; a montagem das 
lâminas com lamínulas histológicas e resina sintética e a análise em microscópio óptico.

A avaliação dos resultados foi realizada de forma semi-quantitativa por meio de escores. Foi avaliada a intensidade de imunomarcação nas células epiteliais e estromais periacinares, utilizando o escore zero para ausência de imunomarcação; um, dois e três para as marcações discreta, moderada e acentuada, respectivamente, conforme critérios adaptados de Rodrigues et al. ${ }^{(2)}$. As amostras foram analisadas por um avaliador, sendo realizada a análise em duplicata, em que os escores de classificação foram estabelecidos para cada um dos fragmentos amostrados.

A análise dos dados do estudo imunoistoquímico foi realizada por meio do teste Kruskal-Wallis e Mann Whitney para a variável intensidade de imunomarcação do anticorpo anti- TGF- $\beta$ entre os diagnósticos. Os dados foram processados nos programas Excel 2010 e SPSS (Statistical Package for the Social Science), versão 16.0, sendo considerado efeito significativo quando $p<0,05$. Sendo os dados apresentados na forma de frequência absoluta e relativa por escore de intensidade de marcação.

\section{Resultados}

Empregando-se a técnica de imunoistoquímica nas amostras de próstata canina normal e com lesões proliferativas, foi obtida imunomarcação citoplasmática para TGF- $\beta$, tanto nas células epiteliais da glândula prostática quanto nas células estromais. A imunomarcação apresentou variação do escore zero ao três de acordo com o tipo celular (epitelial ou estromal) e o diagnóstico (Figuras 1 e 2).

Houve diferença na intensidade de imunomarcação de TGF- $\beta$ nas células epiteliais de acordo com o diagnóstico $(\mathrm{p}<0,05)$. Entretanto, quando considerados os tipos de PIA, não houve diferença. Já para a intensidade de imunomarcação de TGF- $\beta$ nas células estromais periacinares também houve diferença entre os diagnósticos $(\mathrm{p}<0,05)$ (Tabela 1$)$.

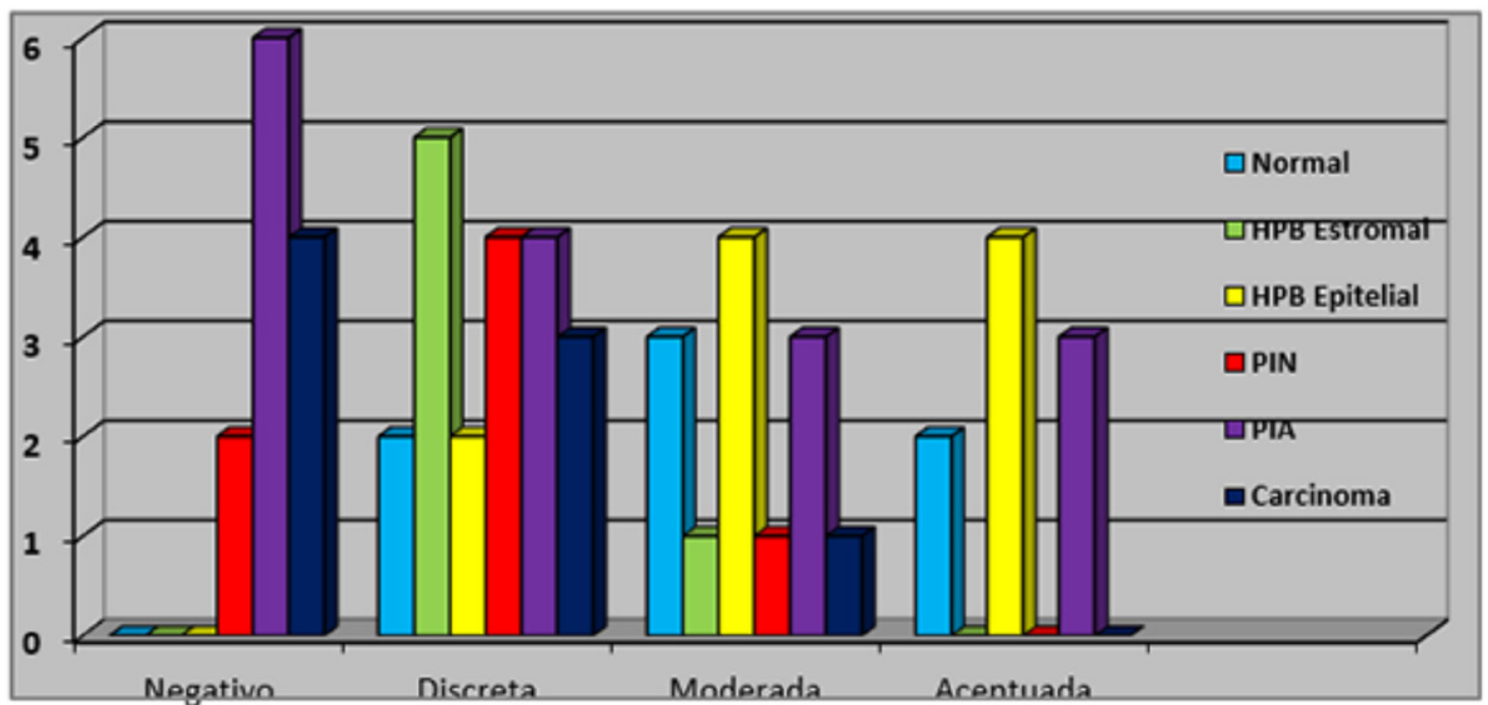

Figura 1. Distribuição dos casos de acordo com os escores para a intensidade de imunomarcação das células epiteliais acinares para TGF- $\beta$ nos diferentes padrões histomorfológicos analisados na próstata do cão, $(\mathrm{p}<0.05)$. 


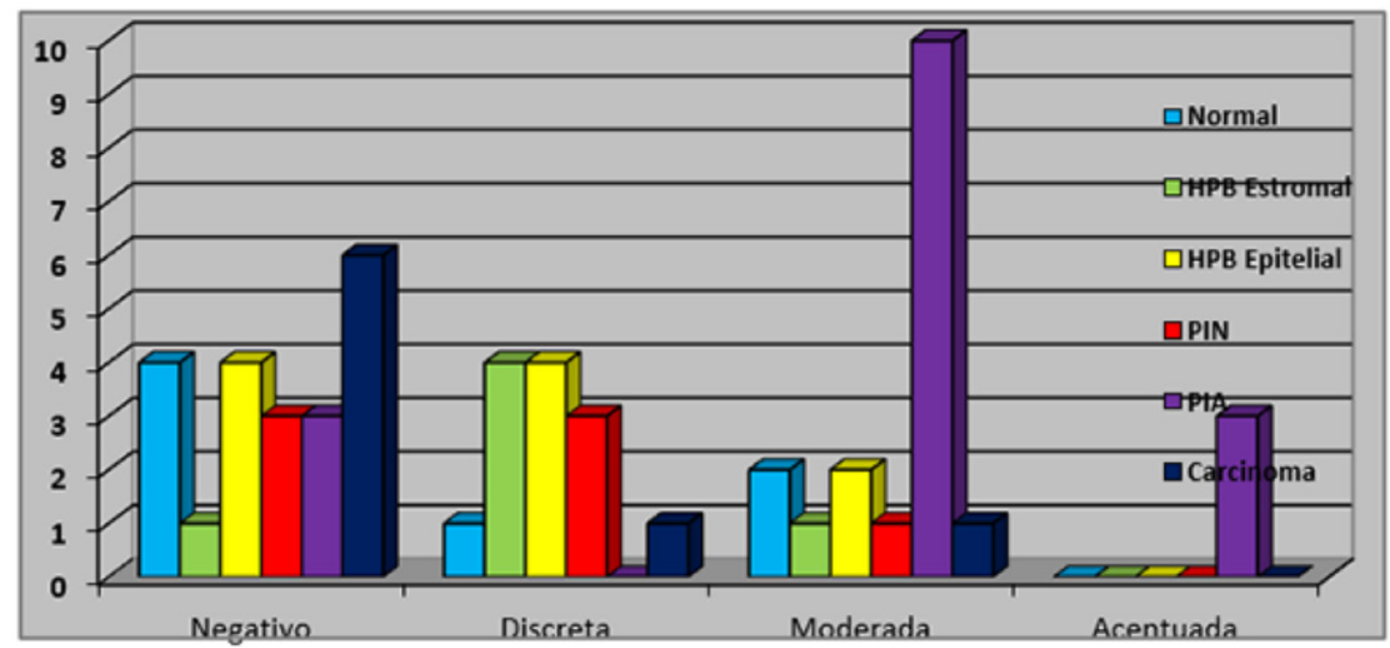

Figura 2. Distribuição dos casos de acordo com os escores para a intensidade de imunomarcação das células estromais periacinares para TGF- $\beta$ nos diferentes padrões histomorfológicos analisados na próstata do cão $(\mathrm{p}<0.05)$.

Tabela 1. Distribuição da frequência absoluta e relativa dos casos de acordo com os escores aplicados à variável intensidade de imunomarcação do anticorpo TGF- $\beta$ nas células epiteliais acinares e estromais periacinares em relação ao padrão histomorfológico

\begin{tabular}{|c|c|c|c|c|c|c|c|c|}
\hline \multicolumn{9}{|c|}{ Células epiteliais $(p=0,006)$} \\
\hline \multirow[b]{2}{*}{ DIAGNÓSTICO } & \multicolumn{2}{|c|}{ Negativo } & \multicolumn{2}{|c|}{ Discreta } & \multicolumn{2}{|c|}{ Moderada } & \multicolumn{2}{|c|}{ Acentuada } \\
\hline & $\mathbf{n}$ & $\%$ & $\mathbf{n}$ & $\%$ & $\mathbf{n}$ & $\%$ & $\mathbf{n}$ & $\%$ \\
\hline NORMALA & - & 0,0 & 2 & 10,0 & 3 & 21,4 & 2 & 25 \\
\hline HPB EPITELIAL ${ }^{B}$ & - & 0,0 & 2 & 10,0 & 4 & 28,6 & 4 & 50 \\
\hline HPB ESTROMAL $L^{c, A, B}$ & - & 0,0 & 5 & 25 & 1 & 7,1 & - & 0,0 \\
\hline PIA DISCRETA ${ }^{\mathrm{D}}$ & 1 & 8,3 & 2 & 10 & 2 & 14,3 & - & 0,0 \\
\hline PIA MODERADA ${ }^{E, B}$ & 3 & 25,0 & 2 & 10,0 & 1 & 7,1 & - & 0,0 \\
\hline PIA ACENTUADA ${ }^{\mathrm{F}}$ & 2 & 16,7 & - & 0,0 & 1 & 7,1 & 2 & 25 \\
\hline $\mathbf{P I N}^{\mathrm{C}, \mathrm{A}, \mathrm{B}}$ & 2 & 16,7 & 4 & 20 & 1 & 7,1 & - & 0,0 \\
\hline CARCINOMA $^{\mathrm{H}, \mathrm{A}, \mathrm{B}}$ & 4 & 33,3 & 3 & 15 & 1 & 7,1 & - & 0,0 \\
\hline & 12 & 100,0 & 20 & 100,0 & 14 & 100,0 & 8 & 100,0 \\
\hline TOIAL & \multicolumn{8}{|c|}{ Células estromais $(p=0,035)$} \\
\hline & \multicolumn{2}{|c|}{ Negativo } & \multicolumn{2}{|c|}{ Discreta } & \multicolumn{2}{|c|}{ Moderada } & \multicolumn{2}{|c|}{ Acentuada } \\
\hline DIAGNÓSTICO & $\mathbf{n}$ & $\%$ & $\mathbf{n}$ & $\%$ & $\mathbf{n}$ & $\%$ & $\mathbf{n}$ & $\%$ \\
\hline NORMAL $^{A}$ & 4 & 19,0 & 1 & 7,1 & 2 & 12,5 & - & 0,0 \\
\hline HPB EPITELIAL ${ }^{B}$ & 4 & 19,0 & 4 & 28,6 & 2 & 12,5 & - & 0,0 \\
\hline HPB ESTROMALC & 1 & 4,8 & 4 & 28,6 & 1 & 6,3 & - & 0,0 \\
\hline PIA DISCRETA ${ }^{\mathrm{D}}$ & 2 & 9,5 & - & 0,0 & 2 & 12,5 & 1 & 33,3 \\
\hline PLA MODERADA ${ }^{\mathrm{E}, \mathrm{B}, \mathrm{C}, \mathrm{G}, \mathrm{H}}$ & - & 0,0 & 1 & 7,1 & 4 & 25,0 & 1 & 33,3 \\
\hline PIA ACENTUADA ${ }^{F, H}$ & 1 & 4,8 & - & 0,0 & 3 & 18,8 & 1 & 33,3 \\
\hline PING & 3 & 14,3 & 3 & 21,4 & 1 & 6,3 & - & 0,0 \\
\hline CARCINOMA $^{\mathrm{H}}$ & 6 & 28,6 & 1 & 7,1 & 1 & 6,3 & - & 0,0 \\
\hline TOTAL & 21 & 100,0 & 14 & 100,0 & 16 & 100,0 & 3 & 100,0 \\
\hline
\end{tabular}

Teste: Kruskal Wallis. No campo diagnóstico, mais de uma letra indica diferença $(p<0,05)$ entre os diagnósticos que as letras representam.

Nas células epiteliais prostáticas o TGF- $\beta$ apresentou imunomarcação citoplasmática (Figura 3). As amostras dePIA, PIN e carcinoma apresentaram maior frequência de casos com escore zero, e desses a maioria não exibiu 
imunomarcação em escore acentuado. O tecido prostático normal e com HPB apresentou imunomarcação para TGF- $\beta$ com os escores variando de um a três para normal e HPB epitelial, e um e dois para HPB estromal. No epitélio acinar foi verificada diferença na imunomarcação de TGF- $\beta$ entre glândulas com HPB estromal, normal e HPB epitelial, com marcação acentuada nos dois últimos tipos. Também houve diferença entre a imunomarcação de TGF- $\beta$ nas amostras de PIN e carcinoma em comparação àquelas normais e com HPB epitelial, nas quais houve maior imunomarcação. Ainda, o TGF- $\beta$ exibiu maior imunomarcação do epitélio acinar nas próstatas com HPB epitelial em relação a PIA moderada (Tabela 1).

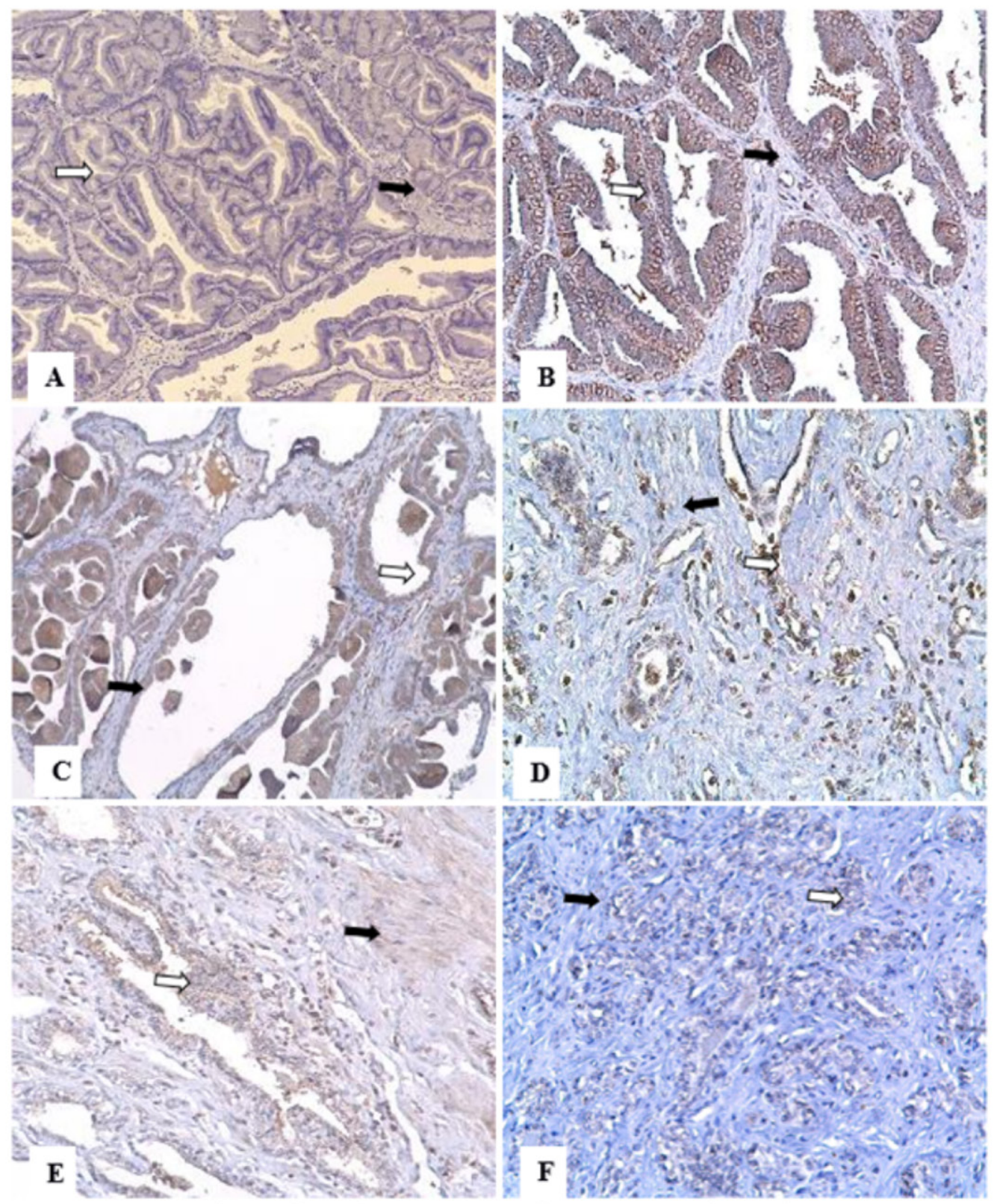

Figura 3. Fotomicrografias da próstata canina. IHQ, anti-TGF- $\beta$. Imunomarcação citoplasmática de células epiteliais (seta vazada) e estromais (seta cheia) A) Próstata normal. Controle negativo, sem imunomarcação 20x. B) Próstata normal. Escore dois para intensidade de imunomarcação. 40x. C) HPB epitelial. Intensidade de imunomarcação com escore dois nas células epiteliais e escore um nas células estromais. 20x. D) PIA Discreta. Intensidade de imunomarcação com escore três nas células epiteliais e dois nas estromais. 20x. E) PIA moderada. Células epiteliais e estromais com escore um para a intensidade de imunomarcação. 20x. F) Carcinoma prostático. Células epiteliais com escore um e estromais com escore zero para a intensidade de imunomarcação. 20x. Advance, DAB, contracoloração Hematoxilina de mayer. 
Nas células estromais da próstata do cão foi observada diferença na imunomarcação do anticorpo antiTGF- $\beta$ entre os diagnósticos selecionados. Foi observada maior imunomarcação de TGF- $\beta$ nas células estromais de glândulas com PIA moderada em relação àquelas com HPB epitelial, HPB estromal, PIN e carcinoma. Também houve diferença na imunomarcação de TGF- $\beta$ em próstatas com PIA acentuada e carcinoma, com menor imunomarcação nas células estromais do tecido prostático com carcinoma. Da mesma forma que o observado para as células epiteliais, não foi observada diferença entre os tipos de PIA. As células estromais periacinares, quando marcadas pelo TGF- $\beta$, apresentaram marcação citoplasmática, principalmente fibroblastos (Figura 3). Houve maior frequência do escore zero nas lesões de PIN e carcinoma. Apenas nas próstatas com PIA foi verificado o escore três de imunomarcação para TGF- $\beta$ nas células estromais, sendo observada marcação citoplasmática nas células do infiltrado inflamatório (Tabela 1).

\section{Discussão}

Nas próstatas caninas avaliadas neste estudo foi observada imunomarcação de TGF- $\beta$ nas células epiteliais e estromais de acordo com o padrão histomorfológico da glândula, havendo positividade nas amostras de próstata normal e com lesões proliferativas benignas (HPB), pré-maligna (PIA e PIN) e malignas (carcinoma). Segundo Niu et al. ${ }^{(11)}$, o TGF- $\beta$ possui funções de inibição da proliferação tecidual, diferenciação, estímulo à apoptose e indução à angiogênese, apresentando, portanto, papel importante na manutenção da homeostase do tecido prostático normal e na progressão de lesões pré-neoplásicas a neoplásicas, o que parece de fato ocorrer no microambiente prostático quando considerados os resultados da imunomarcação de TGF- $\beta$ desta pesquisa no tecido normal e em proliferação da glândula canina.

As amostras de próstata canina normal e com HPB exibiram abundante positividade citoplasmática para TGF- $\beta$ nas células epiteliais e estromais, com destaque ao componente epitelial. Nesse contexto, há descrições de que as concentrações básicas de TGF- $\beta$ são altas no tecido prostático com HPB e seu acúmulo pode contribuir para a progressão da lesão, uma vez que a superexpressão ou a disfunção de fatores de crescimento como o TGF- $\beta$ pode estar relacionada aos mecanismos patológicos da $\mathrm{HPB}^{(15-17)}$. Em contrapartida, Lee et al. ${ }^{(9)}$ referem que o modo de ação do TGF- $\beta$ no tecido prostático é variável, já que na HPB essa citocina atua de modo a manter a homeostase epitelial e, no câncer prostático, além do TGF- $\beta$ apresentar-se em quantidade reduzida, as células neoplásicas podem desenvolver resistência a essa citocina, o que aumenta a possibilidade de desenvolvimento tumoral.

As células epiteliais na próstata canina com PIA moderada apresentaram menor imunoexpressão de TGF- $\beta$ em comparação àquelas com HPB, e as estromais em área de PIA moderada apresentaram maior imunoexpressão dessa citocina do que as demais lesões. Esses resultados corroboram as observações de Rodrigues et al. ${ }^{(2)}$, que referem maior imunomarcação de TGF- $\beta$ no estroma da próstata canina com PIA e concluem que isso implicaria na evolução dessa lesão ao câncer prostático. Ressalte-se que no presente estudo a maior imunomarcação de TGF- $\beta$ no estroma das lesões de PIA decorreu da positividade no citoplasma das células inflamatórias, especialmente linfócitos, que predominam no estroma adjacente do epitélio displásico. Assim, muito embora o TFG- $\beta$ esteja aumentado no estroma da PIA, o mesmo não ocorreu no epitélio displásico correspondente, no qual a ação de inibição da proliferação dessa citocina pode estar limitada ou nula devido às alterações displásicas do mesmo. Essa hipótese ganha respaldo na descrição de Niu et al. ${ }^{(11)}$ sobre a fisiologia do tecido prostático, no qual as células estromais sob influência de andrógenos e fatores de crescimento como o TFG- $\beta$ sinalizam a diferenciação e inibem a proliferação epitelial, enquanto as células epiteliais sinalizam a diferenciação do estroma, especialmente as células musculares lisas. Dessa forma, sugere-se aqui que o epitélio displásico possa exibir alterações funcionais que interfiram nessa dinâmica de 
homeostase, impedindo a inibição da proliferação celular. Ainda, sugere-se que o excesso de TGF- $\beta$ no microambiente inflamatório possa favorecer sua ação funcional angiogênica e, por consequência, a progressão de lesões proliferativas como a PIA. Ainda, Ward ${ }^{(18)}$ afirma que o TGF- $\beta$ induz a produção de p15 e p27, que são proteínas inibidoras do ciclo celular e atuam impedindo ou regulando

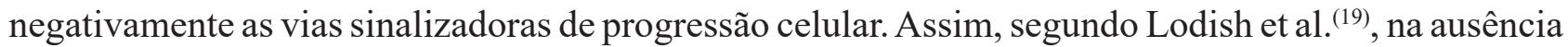
de sinalização de TGF- $\beta$ há contribuição para a proliferação celular anormal e para a malignidade.

Nas amostras de PIN no cão predominaram ausência de reação e discreta imunomarcação para TGF- $\beta$ nas células epiteliais e estromais. Em contraste, ao estudar a PIN de alto grau na próstata de ratos, Wong et al. ${ }^{(20)}$ constataram marcação imunoistoquímica para TGF- $\beta$ nas células estromais adjacentes às células epiteliais displásicas, enquanto no epitélio acinar não foi visualizada imunomarcação da citocina. Com esses resultados, os autores sugeriram o papel do TGF- $\beta$ no estímulo da proliferação celular e no desenvolvimento neoplásico, tendo que sua ausência no epitélio remete à impossibilidade de sua função biológica de inibição da proliferação, o que também foi considerado para as amostras de PIN deste estudo, mesmo diante de discreta imunomarcação nas células epiteliais.

Nas amostras de tecido prostático canino avaliadas neste estudo as células epiteliais apresentaram-se mais intensamente marcadas para TGF- $\beta$ do que as estromais, tanto no tecido normal como neoplásico, o que também foi observado por Perry et al. ${ }^{(21)}$, que realizaram estudo comparativo do TGF- $\beta$ na próstata humana normal e neoplásica.

Neste estudo as amostras de carcinoma prostático apresentaram menor expressão de TGF- $\beta$ em comparação ao tecido normal, tanto nas células epiteliais quanto nas estromais peritumorais. Entretanto, Wolff et al. ${ }^{(22)}$ realizaram estudo imunoistoquímico em neoplasias prostáticas humanas e observaram acentuada imunomarcação para TGF- $\beta$ no tecido neoplásico quando comparado ao tecido prostático normal, o que também fora observado por Rodrigues et al. ${ }^{(2)}$ em próstatas caninas neoplásicas, o que possibilitou aos autores sugerir que as células epiteliais tumorais produzem e secretam essa citocina. De outra parte, a exemplo dos resultados da presente pesquisa, em que houve maior imunomarcação de TGF- $\beta$ no tecido normal e com proliferação benigna (HPB), bem como menor imunomarcação dessa citocina nas lesões pré-malignas e malignas, Lee et al. ${ }^{(9)}$ referem que, no câncer prostático, o TFG- $\beta$ apresenta-se em quantidade reduzida e as células neoplásicas não são afetadas pela citocina, o que aumenta a possibilidade do desenvolvimento neoplásico. Diante desses resultados divergentes, considera-se que são necessárias pesquisas adicionais para esclarecer se a maior ou menor imunomarcação de TGF- $\beta$ nas células neoplásicas da próstata canina reflete atividade tumoral de maior ou menor agressividade, a exemplo do que já fora estudado na próstata humana com câncer, para a qual constatou-se que quanto menor a expressão de TGF- $\beta$, maior o grau de indiferenciação da neoplasia ${ }^{(23)}$.

\section{Conclusão}

Há variação na imunomarcação de TGF- $\beta$ na próstata canina de acordo com o padrão histomorfológico, sendo maior no tecido prostático normal e com lesão proliferativa benigna (HPB) e menor naquele com lesões pré-malignas (PIA e PIN) e malignas (carcinoma), o que indica a ação do TGF- $\beta$ na manutenção da homeostase do tecido normal e com lesão proliferativa benigna e na progressão das lesões proliferativas pré-malignas e malignas da próstata canina. 


\section{Referências}

1. Fonseca Alves CE, Faleiro MBR, Laufer-Amorim R, De Moura VMBD. Avaliação histopatológica da próstata canina de cães adultos sexualmente intactos. Arq. Bras. Med. Vet. e Zoot. 2010; 62(3):596-602.

2. Rodrigues MMP, Di Santis GW, De Moura VMBD, Laufer-Amorim R. COX-2 and TGF- $\beta$ expression in proliferative disorders of canine prostate. Braz. J. Vet. Pathol. 2010; 3:31-36.

3. Toledo DC, Faleiro MBR, Rodrigues MMP, Di Santis GW, Laufer-Amorim R, De Moura VMBD. Caracterização histomorfológica da atrofia inflamatória proliferativa na próstata canina. Ciência Rural. 2010; 40(6):1372-1377.

4. De Marzo AM, Platz EA, Epstein J, Ali T, Billis A, Chan TY, Cheng L, Datta M, Egevad L, Ertoy-Baydar D, Farre X, fine SW, Iczkowski KA, Ittmann M, Knudsen BS, Loda M, Lopez-Beltran A, Magi-Galluzzi C, Mikuz G, Montironi R, Pikarsky E, Pizov G, Rubin MA, Samaratunga H, Sebo T, Sesterhenn IA, Shah RB, Signoretti S, Simko J, Thomas G, Troncoso P, Tsuzuki TT, Van Leenders GJ, Yang XJ, Zhou M, Figg WD, Hoque A, Lucia MS. A working group classification of focal prostate atrophy lesions. Am. J. Surg. Pathol. 2006; 30(10):1281-1291.

5. Bostwick DG, Qian J. High-grade prostatic intraepithelial neoplasia. Modern Pathol. 2004; 17(3):360-379.

6. Cornell KK, Bostwick DG, Cooley DM, Hall G, Harvey HJ, Hendrick MJ, Pauli BU, Render JA, Stoica G, Sweet DC, Waters DJ. Clinical and pathologic aspects of spontaneous canine prostate carcinoma: a retrospective analysis of 76 cases. The Prostate. 2000; 45(1):173-183.

7. Maclachan NJ, Kennedy PC. Tumors of the genital systems. In: Meuten DJ. (Ed.), Tumors in Domestic Animals. Iowa State University Press, Ames, IA, 2002, p. 568-570.

8. Derynck R, Akhurst RJ, Balmain A. TGF- $\beta$ signaling in tumor suppression and cancer progression. Nature Genetics. 2001; 29:117-129.

9. Lee C, Sintich SM, Mathews EP, Shah AH, Kundu SD, Perry KT, Cho JS, Ilio KY, Cronauer MV, Janulis L, Sensibar J. Transforming growth factor- $\beta$ in benign and malignant prostate. Prostate. 1999; 39:285-290.

10. Barnard JA, Lyons RM, Moses HL. The cell biology of transforming growth factor $\beta$. Biochemistry et Biophysics Acta. 1990; 1032:79-87.

11. Niu Y, Xu Y, Zhang J, Bai J, Yang H, Ma T. Proliferation and differentiation of prostatic stromal cells. Brit. J. Urol. 2001; 87:386-393.

12. Sugar LM. Inflammation and prostate cancer. Can. J. Urol. (CJU). 2006; 13(supl.1):46-47.

13. Kononen J, Bubendorf L, Kallioniemi A, Barlund M, Schraml P, Leighton S, Torhorst J, Mihatsch MJ, Sauter G, Kallionimeni OP. Tissue microarrays for high-throughput molecular profiling tumor of specimens. Nature Med. 1998; 4(7):844-847.

14. Bubendorf L, Nocito A, Moch H, Sauter G. Tissue microarray (TMA) technology: miniaturized pathology archives for high-throughput in situ studies. J. Pathol. 2001; 195(1):72-79.

15. Collins AT, Robinson EJ, Neal DE. Benign prostatic stromal cells are regulated by basic ${ }^{\circledR}$ broblast growth factor and transforming growth factor-b. J Endocrin 1996; 151: 315-22

16. Mori H, Make M, Oishi K et al. Increased expression of genes for basic ${ }^{\circledR}$ broblast growth factor and transforming growth factor type 2 in human benign prostatic hyperplasia. Prostate 1990; 16: 71-80 
17. Begun FB, Story MT, Jacobs SC, Hopp KA, Shapiro E, Lawson RK. Regional concentration of genes for basic ${ }^{\circledR}$ broblast growth factor in normal and benign hyperplastic human prostates. J Urol 1995; 153: 839-43

18. Ward LS. Entendendo o Processo Molecular da Tumorigênese. Arq. Bras. Endo. Met. 2002; 46 (4):351360.

19. Lodish H, Berk A, Zipursky SL, Matsudaira P, Baltimore D, Darnell J. Biologia cellular e molecular. 4ed. Rio de Janeiro: REVINTER, 2002. 1084p

20. Wong YC, Xie W, Tsao SW. Structural changes and alteration in expression of TGF- $\beta 1$ and its receptors in prostatic intraepithelial neoplasia (PIN) in the ventral prostate of noble rats. The Prostate. 2000; 45:289-298.

21. Perry KT, Anthony CT, Steiner MS. Immunohistochemical localization of TGF $\beta 1$, TGF $\beta 2$, and TGF $\beta 3$ in normal and malignant human prostate. Prostate. 1997; 33:133-140.

22. Wolff JM, Fandel T, Borchers H, Brehmer Jr B, Jakse G. Transforming growth factor- $\beta 1$ serum concentration in patients with prostatic cancer and benign prostatic hyperplasia. Brit. J. Urol. 1998; 81:403-405.

23. Kim IY, Ahn HJ, Zelner DJ, Shaw JW, Lang S, Kato M, Lee C. Loss of expression of transforming growth factor beta type I and type II receptors correlates with tumor grade in human prostate cancer tissues. Clinical Cancer Research. 1996; 2(8):1255-1261. 